Jurnal Kesehatan Karya Husada, No 7 Vol 2 Tahun 2019

PISSN 2337649X/EISSN 2655-8874

Fitri Handayani', Wa Ode Ikrawati2, Herlin Fitriani "Hubungan Anemia Dan Hipertesni Dengan

Kejadian Bblr Di Puskesmas Wates Kabupaten Kulon Progo" (hal 200-207)

Received

Revisied

Acceptep

10 Desember 2019

20 Februari 2019

16 Juni 2019

\title{
HUBUNGAN ANEMIA DAN HIPERTESNI DENGAN KEJADIAN BBLR DI PUSKESMAS WATES KABUPATEN KULON PROGO
}

\author{
Fitri Handayani ${ }^{1}$, Wa Ode Ikrawati ${ }^{2}$, Herlin Fitriani ${ }^{3}$ \\ ${ }^{1}$ Fakultas Ilmu Kesehatan, Universitas 'Aisyiyah \\ Email:anday971@gmail.com \\ ${ }^{2}$ Fakultas Ilmu Kesehatan, Universitas ‘Aisyiyah \\ Email:waodeikrawati@yahoo.com \\ 3Ilmu Kesehatan, Universitas 'Aisyiyah \\ Email:risanindira@gmail.com
}

\begin{abstract}
ABSTRAK
Latar Belakang: Di Dunia BBLR menempati penyebab kematian bayi pertama dalam periode awal kehidupan. BBLR menyumbang 60\% sampai $80 \%$ darisemua kematian neonatal (WHO, 2015). Angka Kematian Bayi (AKB) di Indonesia menurut hasil survei penduduk antar sensus (SUPAS) 2015 sebesar 22,23 per 1.000 kelahiran hidup (Kemenkes, RI, 2016). Anemia dan hipertensi merupakan salah satu faktor yang dapat mempengaruhi terjadinya BBLR Dwi Purwanto, Anjas (2016) \& Budiastuti. M.D (2014). Tujuan: Penelitian ini bertujuan untuk mengetahui hubungan Anemia dan Hipertensi dengan kejadian BBLR. Metode Penelitian : Penelitian ini menggunakan jenis penelitian kuantitatif dengan rancangan case control dan menggunakan pendekatan restrospektif. Populasi dalam penelitian ini yaitu ibu yang sudah melahirkan bayi selama dua tahun terakhir (2016-2017). Tekhnik pengambilan sampel menggunakan total sampling dengan menggunakan perbandingan 1:1 yaitu $40: 40$ sampel. Hasil: penelitian membuktikan bahwa dengan hasil uji statistik menunjukan bahwa ada hubungan antara anemia dengan kejadian BBLR dengan p-value 0,042 (OR=0,356, $\mathrm{CI}=0,1430,885)$ dan tidak ada hubungan antara hipertensi dengan kejadian BBLR dengan p-value 0,154 ( $\mathrm{OR}=4.030, \mathrm{CI}=0,782-20.760)$. Simpulan dan saran: tidak terdapat hubungan antara umur dan kejadian BBLR dan terdapat hubungan antara paritas dan kejadian BBLR. Diharapkan Perlunya peningkatan pemantauan dan konseling kepada ibu dengan faktor resiko, sehingga dapat mengatasi BBLR dan komplikasi kehamilan dan persalinan lainnya.
\end{abstract}

Kata Kunci: anemia, hipertensi, BBLR

\section{ABSTRACT}

Background: In the LBW in the world determine the cause of death of the first baby in the early period of life. LBW accounts for 60\% to $80 \%$ of all neonatal deaths (WHO, 2015). Infant Mortality Rate (IMR) in Indonesia based on the results of 2015 inter-census population survey 
Jurnal Kesehatan Karya Husada, No 7 Vol 2 Tahun 2019

PISSN 2337649X/EISSN 2655-8874

Fitri Handayani', Wa Ode Ikrawati', Herlin Fitriani "Hubungan Anemia Dan Hipertesni Dengan

Kejadian Bblr Di Puskesmas Wates Kabupaten Kulon Progo" (hal 200-207)

(SUPAS) of 22.23 per 1,000 live births (Ministry of Health, RI, 2016). Anemia and hypertension are one of the factors that can cause LBW Dwi Purwanto, Anjas (2016) \& Budiastuti. M.D (2014). Objective: This study aims to study the relationship between anemia and hypertension with LBW events. Research Methods: This study uses quantitative research with case control design and uses retrospective findings. The population in this study are mothers who have given birth to babies during the last two years (2016-2017). The technique of taking samples using total sampling using 1: 1 which is 40: 40 samples. Results: the research proves the research shows the relationship between anemia with $L B W$ incidence with $p$-value 0.042 (OR $=0.356, C I$ $=0.1430 .885)$ and there is no relationship between hypertension and $L B W$ incidence with p-value $0.154(O R=4.030, C I=0.782-20.760)$. Conclusions and suggestions: there is no relationship between age and $L B W$ events and there is a relationship between parity and $L B W$ events. Expected from the increase and counseling in mothers with risk factors, so that it can overcome $L B W$ and other complications of pregnancy and childbirth.

Keywords: anemia, hypertension, BBLR

\section{PENDAHULUAN}

Angka kematian Bayi (AKB) merupakan salah satu indikor penting dalam menentukan derajat kesehatan masyarakat. Angka Kematian Bayi (AKB) dunia masih terbilang tinggi yaitu 37 per 1000 kelahiran hidup (WHO. 2015). AKB di Negara negara Assosiation of Southeast Asian Nations (ASEAN) tahun 2015, Singapura 2 per $1000 \mathrm{KH}$, Brunei Darussalam 9 per $1000 \mathrm{KH}$, Malaysia 6 per $1000 \mathrm{KH}$, Thailand 11 per $1000 \mathrm{KH}$, Vietnam 17 per $1000 \mathrm{KH}$, Filipina 22 per $1000 \mathrm{KH}$, Indonesia 22 per $1000 \mathrm{KH}$ (World Bank, 2015). Menurut laporan World Health Organization (WHO) tahun 2015, Kematian neonatal menyumbang $45 \%$ kematian di bawah lima tahun pada tahun 2015 . Penyebab utama kematian neonatal pada tahun 2015 adalah komplikasi kelahiran BBLR 16\%, komplikasi terkait intrapartum $11 \%$, sepsis $7 \%$, anomaly congenital $5 \%$, pneumonia $3 \%$, lain-lain $3 \%$, tetanus $1 \%$. BBLR menempati penyebab kematian bayi pertama di dunia dalam periode awal kehidupan. BBLR menyumbang $60 \%$ sampai $80 \%$ dari semua kematian neonatal. Prevalensi global BBLR adalah 20 juta pertahun atau $15,5 \%$ dari seluruh bayi lahir di dunia (WHO, 2015). Angka Kematian Bayi (AKB) di Indonesia menurut hasil survei penduduk antar sensus (SUPAS) 2015 sebesar 22,23 per 1.000 kelahiran hidup Begitu pula dengan Angka Kematian Balita (AKABA) hasil SUPAS 2015 sebesar 26,29 per 1.000 kelahiran (Kemenkes, RI. 2016.) Berat Badan Lahir Rendah (BBLR) adalah bayi yang lahir dengan berat badan sama atau kurang dari 2500 gram (WHO. 2014). Anemia dan hipertensi merupakan faktor yang dapat mempengaruhi terjadinya BBLRDwi Purwanto, Anjas (2016) \& Budiastuti. M.D (2014) Berdasarkan data berat bayi lahir rendah DIY 2016 dari kabupaten dengan jumlah kasus BBLR tertinggi hingga terendah yaitu : Kulon progo $7,47 \%$, gunung Kidul 6,68\%, Yogyakarta 5, $47 \%$, Sleman 4,84, Bantul 3,66 \%. Angka BBLR di Kabupaten Kulon Progo pada tahun 2014 $7,11 \%$, tahun 2015 6,95\%, tahun 2016 $7,47 \%$, walaupun pada tahun 2014 ke tahun 2015 terjadi penurunan angka BBLR, tetapi pada tahun 2015 ke 2016 ada peningkatan 
jumlah kasus BBLR yaitu dari 6,95\% menjadi 7,47\% (Dinas Kesehatan DIY, 2016). Data Bayi yang lahir di Kabupaten Kulon Progo tahun 2017 dengan berat badan lahir rendah (BBLR) sejumlah 332/ $6,69 \%$. Kasus BBLR terdapat di semua wilayah kerja puskesmas se-Kabupaten Kulon Progo dengan jumlah kasus BBLR $>23$ berada di wilayah Wates, dan Pengasih II; dengan jumlah kasus BBLR antara 2319 berada di wilayah Panjatan I, Kokap I dan Nanggulan ( Profil Kesehatan Kabupaten Kulon Progo, 2017) Berdasarkan hasil studi pendahuluan yang dilakukan di Puskesmaas wates terdapat beberapa kejadian BBLR dengan umur ibu yang beresiko dan paritas ibu > 3. Sehingga peneliti tertarik untuk melakukan penelitian tentang hubungan Umur dan paritas ibu dengan Kejadian BBLR di Puskesmas Wates Kabupaten Kulon

\section{METODE PENELITIAN}

Penelitian ini merupakan penelitian kuantitatif dengan rancangan penelitian Case control dan menggunakan pendekatan retrospektif. Penelitian dilakukan selama 3 bulan pada tanggal 27 Februari-10 Mei 2018. Populasi dalam penelitian ini adalah semua ibu yang sudah melahirkan bayi selama dua tahun terakhir (2016-2017) di puskesmas Wates Kulon Progo. Penelitian ini menggunakan dua kelompok, kelompok kasus yaitu ibu yang melahirkan bayi BBLR dan kelompok kontrol yaitu ibu yang melahirkan bayi normal. Sampel penelitian ini yaitu 1:1 pada kelompok kasus berjumlah 40 yang diambil secara total sampling dan kelompok kontrol 40 yang diambil secara random. Metode pengumpulan data menggunakan data sekunder yaitu kohort dan rekam medis di Puskesmas Wates Tahun 2016-2017 dengan menggunakan kuesioner. Analisis data yaitu analisis univariat dan bivariat dengan menggunakan uji Chi-Square. Penelitian ini mendapatkan izin dari komisi etik penelitian Universitas 'Aisyiyah Yogyakarta dengan Nomor : 16/KEPUNISA/Exe./II/201

\section{HASIL DAN PEMBAHASAN}

\section{HASIL PENELITIAN}

\section{a. Analisa Univariat}

\section{Tabel 1. Distribusi Frekuensi Karakteristik Responden}

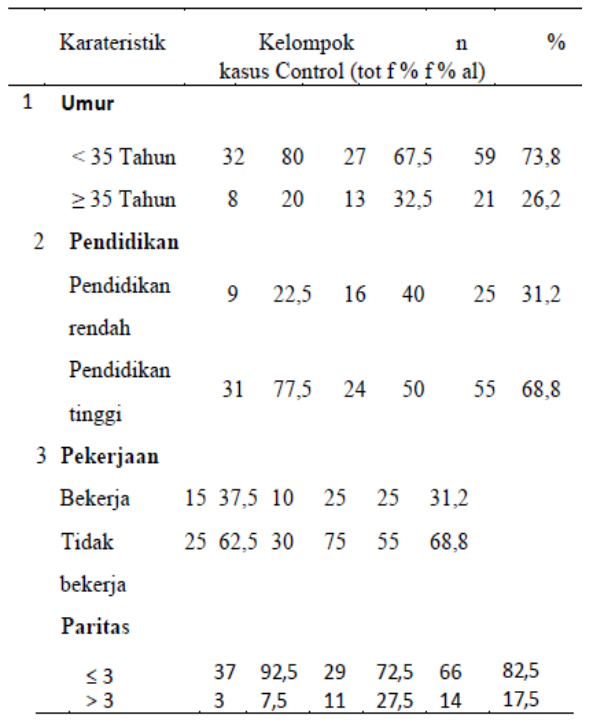

Di dapatkan bahwa, dari 80 ibu yang menjadi responden di PuskesmasKabupaten Kulon Progo sebagian besar umurnya $<35$ tahun yaitu berjumlah 59 responden dengan persentase $73,8 \%$ dan umur $\geq 35$ tahun yaitu berjumlah 21 responden dengan persentase 26,2\%. Untuk karateristik pendidikan, sebagian besar responden pendidikannya yaitu pendidikan tinggi dengan jumlah 55 responden dengan persentase $68,8 \%$ dan untuk pendidikan rendah berjumlah 25 responden dengan persentase $31,2 \%$. Untuk karateristik pekerjaan, sebagian besar responden 
pekerjaannya yaitu tidak bekerja sebanyak 55 responden dengan persentase $68,8 \%$ dan untuk responden yang bekerja berjumlah 25 dengan persentase $31,2 \%$. Untuk karateristik paritas, sebagian besar responden dengan paritas $>3$ sebanyak 14 dengan persentase $17,5 \%$ dan responden dengan paritas $\leq 3$ sebanyak 66 dengan responden $82,5 \%$

\section{B.Analisis Bivariat}

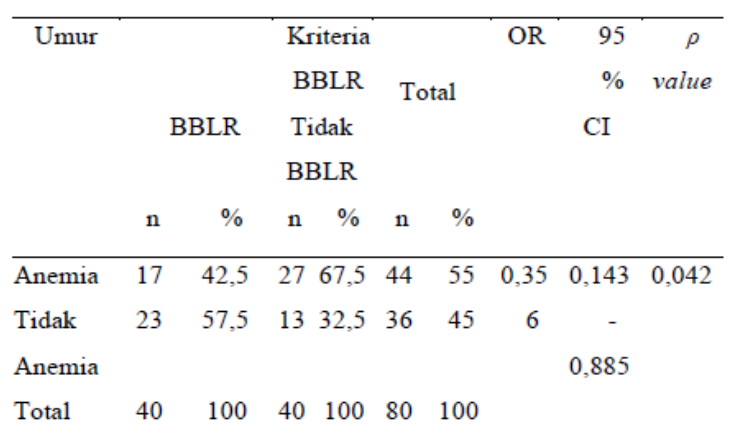

Tabel 2. Hubungan Anemia dengan Kejadian BBLR

\section{Tabel 2. Hubungn Hipertensi dengan Kejadian BBLR}

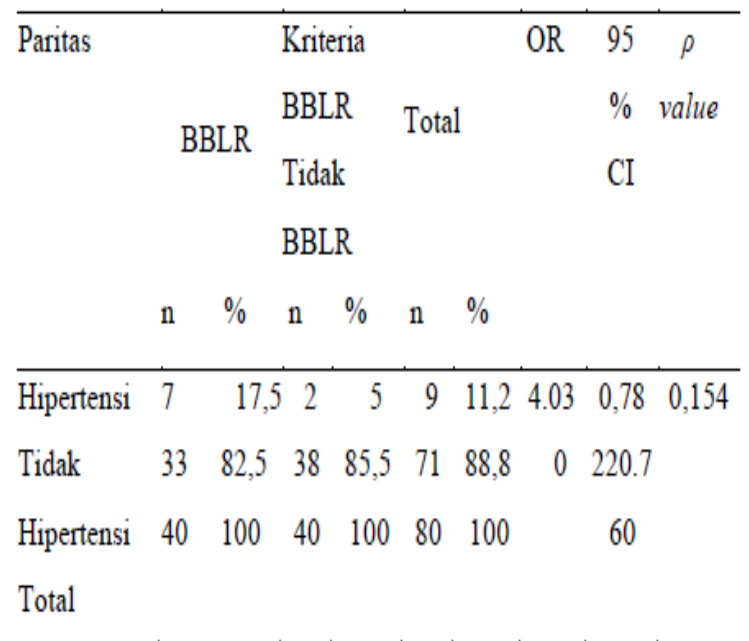

Berdasarkan Tabel 2 Menyatakan ibu yang melahirkan bayi BBLR dengan Hipertensi sebanyak $7(17,5 \%) \quad$ dan ibu yang melahirkan bayi BBLR dengan tidak hipertensi sebanyak $33(82,5 \%)$. Sedangkan untuk kasus kontrol menyatakan ibu yang melahirkan bayi tidak BBLR dengan Hipertensi sebanyak 2 ( 5\%) dan untuk ibu yang melahirkan bayi tidak BBLR dengan tidak hipertensi sebanyak $71(88,8 \%)$. Dari total 80 responden $(100 \%)$ nilai significancy pada hasil menunjukan $p$-value $0,154 \quad(\mathrm{OR}=4.030, \mathrm{CI}=0,782-20.760)$. Hal ini menunjukan tidak ada hubungan antara Hipertensi ibu dengan Kejadian BBLR di Puskesmas Wates Kabupaten Kulon Progo tahun 2018

\section{PEMBAHASAN}

Anemia mempunyai pengaruh terhadap kehamilan dan persalinan ibu. Anemia adalah suatu kondisi dimana kadar hemoglobin $(\mathrm{Hb})$ dalam kehamilan disebabkan kekurangan zat besi yang dapat menimbulkan gangguan atau hambatan pada pertumbuhan janin baik sel tubuh maupun sel otak. Hal ini dapat meningkatkan resiko morbiditas dan mortilitas ibu dan bayi.Kemungkinan melahirkan BBLR juga lebih besar (Arista, 2012). Menurut Mufdlilah (2009), Anemia dalam kehamilan ditegakkan jika kadar $\mathrm{Hb}$ $<11 \mathrm{~g} \%$ pada trimester pertama dan ketiga, dan $\mathrm{Hb}<10,5$ gr\% pada trimester kedua. Jika kadar $\mathrm{Hb}<8$ gr\% perlu dilakukan pengobatan selanjutnya dengan diberikan suplemen zat besi dan penyuluhan gizi. Untuk mencegah anemia pada ibu hamil, tenaga kesehatan sebaiknya memberikan tablet zat besi minimal 90 tablet selama kehamilan. Dalam meminum tablet zat 
Jurnal Kesehatan Karya Husada, No 7 Vol 2 Tahun 2019

PISSN 2337649X/EISSN 2655-8874

Fitri Handayani', Wa Ode Ikrawati', Herlin Fitriani "Hubungan Anemia Dan Hipertesni Dengan

Kejadian Bblr Di Puskesmas Wates Kabupaten Kulon Progo" (hal 200-207)

besi, anjurkan ibu tidak meminumnya bersamaan dengan teh, kopi atau susu karena dapat menghambat penyerapan zat besi dalam darah. Tenaga kesehatan dan suami/keluarga juga harus memastikan bahwa tablet zat besi betulbetul diminum oleh ibu Bayi berat lahir rendah (BBLR) merupakan berat badan bayi saat lahir kurang dari 2500 gram tanpa memandang masa gestasi, bisa terjadi pada bayi cukup bulan ataupun prematur. BBLR akan menjadi masalah kesehatan masyarakat secara global baik jangka pendek maupun jangka panjang. (WHO, 2014, Unicef. 2017) Pada penelitian ini didapatkan bahwa Anemia berhubungan dengan kejadian BBLR yaitu p-value 0,042 (OR=0,356, CI=0,143-0,885) yang artinya hasil dari peneitian dengan teori sejalan yaitu anemia pada ibu berhubungan dengan kejadian BBLR. Hasil penelitian ini diperkuat oleh penelitian yang dilakukan oleh Ling Ling Huang, et.al. (2015) mendapatkan hasil bahwa, kejadian persalinan prematur dan bayi dengan berat lahir rendah secara signifikan lebih banyak pada ibu yang mengalami anemia pada trimester ketiga kehamilan. Sedangkan menurut Shoboo Rahmati. Et.al (2017) anemia pada trimester 1 , trimester II, dan trimester III yang lebih mempengaruhi untuk terjadinya BBLR adalah anemia pada trimester I. Menurut Ketut Labir, dkk (2013) mengatakan ibu hamil yang mengalami anemia trimester I berisiko 10 kali lebih besar untuk melahirkan bayi BBLR dibandingkan yang ibu hamil tidak anemia, sedangkan ibu hamil yang mengalami anemia trimester II memiliki risiko 16 kali lebih besar untk melahirkan bayi BBLR dibandingkan ibu hamil yang tidak anemia. Hasil pesenelitian dari Nair M et al 2018 bahwa Ibu dengan anemia selama kehamilan ditemukan memiliki risiko 4,3 kali lebih tinggi melahirkan bayi berat lahir rendah dibandingkan dengan ibu yang tidak anemia. Dari hasil penelitian yang ada dapat disimpulkan bahwa ibu yang mengalami anemia memiliki resiko untuk melahirkan bayi dengan beratbadan lahir rendah Hipertensi adalah peningkatan tekanan darah sistolik $\geq 30 \mathrm{mmHg}$ dan diastolic $\geq 15$ $\mathrm{mmHg}$ atau tekanan darah $\geq 140 / 90 \mathrm{mmHg}$ (Benson and Pernoll's, 2009). Hipertensi dalam kehamilan, perlu penanganan khusus karena dapat menurunkan aliran darah ke plasenta, yang akan mempengaruhi persediaan oksigen dan nutrisi pada bayi. Hal ini akan memperlambat pertumbuhan bayi dan meningkatkan risiko saat melahirkan. Pada penelitian ini didapatkan bahwa Hipertensi tidak sesuai dengan teori yang ada yaitu tidak ada hubungan antara hipertensi dengan kejadian BBLR yaitu 
Jurnal Kesehatan Karya Husada, No 7 Vol 2 Tahun 2019

PISSN 2337649X/EISSN 2655-8874

Fitri Handayani', Wa Ode Ikrawati', Herlin Fitriani "Hubungan Anemia Dan Hipertesni Dengan

Kejadian Bblr Di Puskesmas Wates Kabupaten Kulon Progo" (hal 200-207)

pvalue 0,037 (OR=214, $\mathrm{CI}=055-838)$. Hasil penelitian ini sejalan dengan penelitian yang dilakukan oleh Fatima J 2016 bahwa tidak ada hubungan antara tekanan darah dengan kejadian BBLR di Puskesmas Bangetayu, dapat dilihat dengan nilai $\mathrm{p}$ sebesar 1,000 ( $p>0,05)$ dan nilai OR sebesar 0,731 yang artinya bahwa tidak ada hubungan antara tekanan darah dengan kejadian BBLR di wilayah Kerja Puskesmas Bangetayu), Menurut Melycha 2014 bahwa Hasil penelitian menunjukkan bahwa 364 ibu melahirkan diketahui $77,74 \%$ ibu dengan riwayat hipertensi dalam kehamilan dan 50\% bayi BBLR. Hasil uji analisis chisquare menunjukkan bahwa nilai Xhitung > Xtabelsebesar 12,03 dengan Pvalue $=0,001(\mathrm{p}<0,05)$, OR: 0,47 CI $95 \%(0,3-0,7)$ sehingga dapat disimpulkan bahwa ada hubungan hipertensi dalam kehamilan dengan berat bayi lahir rendah. Ibu dengan hipertensi dalam kehamilan 0,47 kali berisiko melahirkan bayi dengan BBLR. Hipertensi dalam kehamilan memiliki hubungan dengan kejadian berat bayi lahir rendah akan tetapi tidak semua ibu hamil dengan hipertensi dalam kehamilan akan melahirkan bayi dengan BBLR

\section{SIMPULAN DAN SARAN}

\section{SIMPULAN}

Terdapat hubungan antara anemia ibu dengan kejadian BBLR dengan nilai significancy pada hasil menunjukan $\mathrm{p}$ value 0,0-42 dan tidak terdapat hubungan antara hipertensi yang dialami ibu dengan kejadian BBLR. Dengan nilai significancy pada hasil menunjukan $p$-value 0,154 .

\section{SARAN}

Perlu adanya pengukuran dan pemantauan secara langsung terhadap ibu selama proses kehamilan dan pengontrolan yang lebih intensif kepada ibu hamil terkait ante natal care. Hal ini bertujuan untuk menambah wawasan ibu agar dapat mengurangi atau bahkan menghilangkan resiko selama kehamilan

\section{DAFTAR PUSTAKA}

Atikah P (2010). BBLR (Berat Badan Lahir Rendah). Yogyakarta. Muha Medika.

Dinas Kesehatan DIY. (2016)

Dwi Purwanto, Anjas. 2016. Faktor resiko yang berhubungan dengan kejadian bayi berat lahir rendah. Universitas Airlangga Fakultas Kesehatan Masyarakat Surabaya

Effendi, F \& Makhfudli. (2009). Keperawatan Kesehatan

Komunitas: Teori dan Praktek 
Jurnal Kesehatan Karya Husada, No 7 Vol 2 Tahun 2019

PISSN 2337649X/EISSN 2655-8874

Fitri Handayani', Wa Ode Ikrawati', Herlin Fitriani "Hubungan Anemia Dan Hipertesni Dengan

Kejadian Bblr Di Puskesmas Wates Kabupaten Kulon Progo" (hal 200-207)

Dalam Keperawatan. Jakarta:

Salemba medika.

Fatima J. 2016. Fakto Faktor

Yang Berhubungan Dengan

Kejadian Berat Badan Lahir

Rendah Di Wilayah Kerja

Puskesmas Bangetayu Kota

Semarang Tahun 2016.

Jurnal Kesehatan Masyarakat

(E-Journal).

http://ejournal3.undip.ac.id/inde

x.php/jk m

Gruchala, et.al., (2015). Short Interpregnancy Interval and Low

Birt Weigth: A Role of Parity.

Am J Hum Biol, 27 (5): 666-6

Ketut Labir, dkk. (2013). Anemia ibu hamil trimester I dan II meningkatkan risiko kejadian berat bayi lahir rendah di RSUD Wangaya

Denpasar. Public Health and

Preventive Medicine Archive,

Volume 1, Nomor 1, Juli 2013

Kristiana, Noni dan Juliansyah, Elvi

(2017). Umur, Pendidikan,

Pekerjaan Dan

Pengetahuan Dengan Kejadian Berat Badan

Lahir Rendah (BBLR). Program

Studi Kesehatan Masyarakat,

STIKes Kapuas Raya Sintang
LingLing Huang, et.al. (2015). The Influence of Iron-deficiency Anemia during the Pregnancy on Preterm Birth and Birth Weight in South China. SciEP. Science and Education Publishing

Melycha A. 2014. hubungan hipertensi dalam kehamilan dengan berat bayi lahir rendah di RSUD Wates Kabupaten Kulon

ProgoYogyakarta.http://etd.repository.ugm. ac.id/index.php?mod=penelitian _detail\&sub=Penelitian Detail \&act=view\&typ=html\&buku_id =97 509\&o byek_id=4

Nair M, Gireesh S, Yakoob R, Cherian NC.

2018. Effect of maternal anaemia on birth weight of term babies. India; Int J Contemp Pediatr

Nurseha, A. Z. B. (2017). Faktor-Faktor Yang Berhubungan Dengan Kejadian BBLR.JHealth.4:250257.

Profil Kesehatan Kabupaten Kulon Progo. (2017).

Unicef. (2017). Data: Monitoring the Situation of Children and Women (Diakses pada tanggal 25 November Page 206 | 
Jurnal Kesehatan Karya Husada, No 7 Vol 2 Tahun 2019

PISSN 2337649X/EISSN 2655-8874

Fitri Handayani', Wa Ode Ikrawati², Herlin Fitriani 'Hubungan Anemia Dan Hipertesni Dengan

Kejadian Bblr Di Puskesmas Wates Kabupaten Kulon Progo" (hal 200-207)

2017)https://data.unicef.org/topi c/nutrition/low birthweight/\#)

Wiknjosastro, Hanifa. (2009). Ilmu Kebidanan. Jakarta: Yayasan Bina Pustaka Sarwono Prawirohardjo;

WHO. (2015). World Health statistics. (Diakses pada tanggal 5 Desember 2017 http://apps.who.int/iris/bitstream $/ 10$

$665 / 170250 / 1 / 9789240694439$ eng. pdf)

World Bank, 2015. Data Value. Tersedia: http://data.worldbank.org/indicat or/

SP.DYN.LE00.IN?order=wbapi _dat a_value _2013+wbapi_data_value+wbap i_d aa_valu e-last\&sort=asc.

WHO, (2015). Maternal, newborn, child and adolescent health. 2017 (Diakses pada tangga 15 Desember 2017 http://www.who.int/maternal_ch ild_adolescent/newborns/prematurit y/en/ )

Kemenkes, RI. (2016). Profil Kesehatan Indonesia. Jakarta
WHO. (2014). Global Nutrition Targets 2025 Low Birth Weight Policy Brief. (Diakses pada tanggal $25 \quad$ November 2017bhttp://apps.who.int/iris/bit stream/10665/149020/2/WHO_ NMH_NHD_14.5_eng.p df?ua=1 )

WHO. (2014). Global Nutrition Targets 2025 Low Birth Weight Policy Brief. (Diakses pada tanggal $25 \quad$ November 2017http://apps.who.int/iris/bitst ream/10665/149020/2/WHO_NM H_NHD_14.5_eng.p df?ua=1 )

Zaenab. (2006). Beberapa Faktor resiko kejadian BBLR di Rumah Sakit Al Fatah Ambon Periode januari-desember. Skripsi. RS Al Fatah Ambon 